\title{
Effect of statin therapy on the progression of coronary atherosclerosis
}

\author{
Jinwei Tian', Xia Gu', Yanli Sun', Xiang Ban², Yun Xiao ${ }^{3}$, Sining $\mathrm{Hu}^{1}$ and Bo Yu*
}

\begin{abstract}
Background: An increasing number of authors employing intravascular ultrasound (IVUS) and virtual histology (VH-IVUS) have investigated the effect of statin use on plaque volume (PV) and plaque composition. However, inconsistent results have been reported. Therefore, we conducted a meta-analysis to determine the appropriate regimen of statins to effectively stabilize vulnerable coronary plaques.

Methods: Online electronic databases were carefully searched for all relevant studies. We compared mean values of PV and plaque composition between baseline and follow-up in patients receiving statin therapy. We pooled treatment effects and calculated mean differences (MD) with the 95\% confidence interval (Cl) using a random-effects model. By stratified analyses, we explored the influence of clinical presentation, dose and duration of statin treatment, and low-density lipoprotein-cholesterol (LDL-C) levels on the effects of statins.

Results: Seventeen studies involving 2,171 patients were analyzed. Statin therapy significantly decreased PV $\left(-5.3 \mathrm{~mm}^{3} ; 95 \% \mathrm{Cl}:-3.3 \mathrm{~mm}^{3}\right.$ to $\left.-7.2 \mathrm{~mm}^{3} ; P<0.001\right)$, without heterogeneity. When considering the dose and duration of statins used, only subgroups employing a high dose and long duration demonstrated a significant reduction in PV $(p<0.001)$. A significant decrease in PV was noted if achieved LDL-C levels were $<100 \mathrm{mg} / \mathrm{dL}$ $(p<0.001)$. Statin treatment could induce a twofold decrease in PV in patients with acute coronary syndrome (ACS) compared with that observed in patients with stable angina pectoris (SAP). A regressive trend was seen for necrotic core volume (MD: $-2.1 \mathrm{~mm}^{3} ; 95 \% \mathrm{Cl}:-4.7 \mathrm{~mm}^{3}$ to $0.5 \mathrm{~mm}^{3}, P=0.11$ ). However, statin use did not induce a significant change for fibrotic, fibro-fatty, or dense calcium compositions.
\end{abstract}

Conclusions: Our meta-analysis demonstrated that statin therapy (especially that involving a high dose and long duration and achieving $<100 \mathrm{mg} / \mathrm{dL}$ LDL-C levels) can significantly decrease PV in patients with SAP or ACS. These data suggested that statins can be used to reduce the atheroma burden for secondary prevention by appropriately selecting the statin regimen. No significant change in plaque composition was seen after statin therapy.

Keywords: Atherosclerosis, Statin, Meta-analysis, Intravascular ultrasound

\section{Background}

Statin treatment is regarded as one of the most effective methods for the stabilization of vulnerable atherosclerotic plaques, and is associated with improvements in outcome in patients with coronary heart disease (CHD) $[1,2]$. Statins have a wide range of biologic effects, including a decrease in the level of low-density lipoprotein-cholesterol (LDL-C) and high-sensitivity C-reactive

\footnotetext{
*Correspondence: yubodr2009@163.com

${ }^{1}$ Key Laboratories of Education Ministry for Myocardial Ischemia; Department of Cardiology, Second Affiliated Hospital of Harbin Medical University, Harbin 150086, P.R. China

Full list of author information is available at the end of the article
}

protein, as well as a modest increase in the level of highdensity lipoprotein-cholesterol [3]. With respect to secondary prevention, statins are considered to be essential in subjects with CHD [4].

Outcomes have been shown to be improved after statin treatment, but the mechanism by which statins confer cardiovascular benefit is not precisely understood. Some angiographic studies have shown only minimal increases in lumen area in target lesions in patients administered statins [5]. Regression of coronary plaque volume (PV) and plaque composition as well as a reduction in plaque vulnerability are presumed to have important roles. One study employing a meta-analysis

\section{Biomed Central}


reported a significant reduction in plaque size after statin treatment [6], whereas no significant decrease in plaque size was shown by subgroup analyses according to follow-up time of statin use and LDL-C levels, suggesting that these results were not robust. An increasing number of intravascular ultrasound (IVUS) and virtual histology-intravascular ultrasound (VH-IVUS) studies have demonstrated that statin therapy can result in significant changes in PV and plaque composition $[7,8]$. However, not all studies have suggested that statin therapy can induce a significant reduction in the size and composition of plaques. These differences among studies may be due to different statin-administered strategies. Therefore, determining which regimen of statin administration is effective for stabilizing vulnerable coronary plaques is very important.

In the present study, we aimed to summarize the evidence on the effectiveness of statins on atherosclerosis development. We also sought to determine the extent to which such statin-induced changes in plaque composition was supported by evidence. We therefore undertook a meta-analysis to investigate if statin therapy can significantly change PV and plaque composition. By stratified analyses, we further explored the influence of clinical presentation, dose and duration of statin treatment, and LDL-C levels at follow-up upon the effects of statins.

\section{Methods}

\section{Search strategies}

The online electronic databases PubMed, EMBASE, and Cochrane Clinical Trials were searched carefully using the following terms: "Intravascular ultrasound" or "IVUS" and "HMG-CoA reductase inhibitor (s)", or "statin(s)", or "atorvastatin" or "pravastatin" or "simvastatin" or "cerivastatin" or "fluvastatin" or "lovastatin" or "mevastatin" or "pitavastatin" or "rosuvastatin". The date range was 1990-2010 and there were no language restrictions. The literature search was accomplished independently by two well-trained reviewers. Discussions between the two reviewers were initiated if there were discrepancies in search results. Abstracts of conferences and recently published editorials were checked, as were the reference lists of identified articles and review articles.

\section{Inclusion criteria}

The inclusion criteria for the meta-analysis were: (1) IVUS and/or VH-IVUS volume analyses at baseline and follow-up; (2) $\geq 1$ statin therapy group.

\section{Exclusion criteria}

Reviews, commentaries, editorials and case reports were not used. Studies analyzing other drugs, stents, graft disease, in-stent neointima and animal models were also excluded. We also excluded studies in which: there was no follow-up; not all patients were evaluated by IVUS or VH-IVUS; the volumetric parameters of plaques were not reported.

\section{Selection of studies}

Two reviewers independently reviewed the articles. Study selection is summarized in Figure 1. Of 248 relevant studies, 213 were excluded (Figure 1). Of the remaining 35 potentially appropriate studies, 18 were excluded. Of these, 8 studies detected area measurements or did not provide absolute volume measurements; 4 carried out post-hoc analyses using experimental data from other studies which were included in our analyses; 2 measured the remodeling index ; 1 chose the coronary flow reserve index as the endpoint; 1 investigated patients with diabetes mellitus; 1 undertook IVUS at one time point; 1 considered cerivsatatin [9] (which was withdrawn from the market in 2001 due to its association with fatal rhabdomyolysis) only in the Discussion section. Consequently, 17 studies including 22 groups with 2,171 subjects were analyzed [10-26].

The main analysis of our study focuses on pre October 2010 papers but that since then 5 studies with 7 groups [27-31] were published whose principal findings were shown in the in Additional file 1: Table S1 and Additional file 2: Table S2 but were not included in the formal analysis.

\section{Data extraction}

Two reviewers independently extracted the following variables: (i) first author's surname and year of publication of article; (ii) characteristics of the study population (sample size, age, sex, presentation); (iii) type and dose of statin; (iv) duration of follow-up; (v) LDL-C levels at baseline and follow-up; (vi) VH-IVUS volume data. Inconsistencies in the interpretation of data were discussed until a consensus was reached. If a study lacked complete data, the investigators of the primary study were contacted to provide information.

The methodological quality of the studies included in the meta-analysis was independently scored by two reviewers using a validated five-point scale created by Jadad et al. The scale consists of three items describing randomization ( $0-2$ points), masking ( $0-2$ points), and dropouts and withdrawals (0-1 points) in the report of a randomized controlled trial [20]. A score of 1 is given for each of the points described. An additional point is obtained if the method of randomization and/or blinding is given and is appropriate, whereas one point is deducted if it is inappropriate. Higher scores indicate better reporting. 


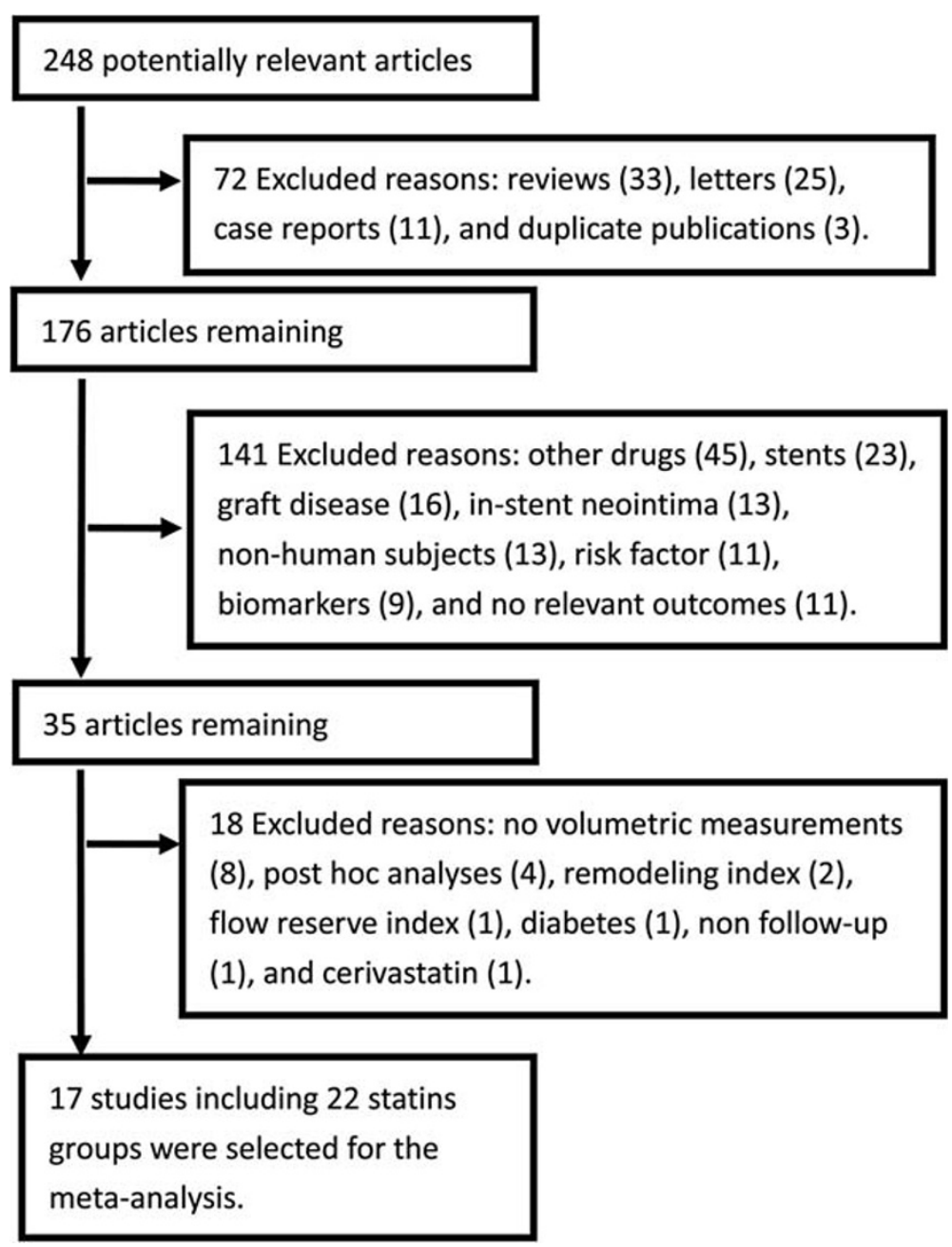

Figure 1 Study selection.

\section{Endpoints}

Before IVUS analyses, based on reproducible landmarks (e.g., a calcium deposit, stent edge or side branch), the same segment was identified in the IVUS run at baseline and at follow-up. IVUS analyses were undertaken once at baseline and at follow-up by the same independent experienced investigator who was blinded to the patient groups. Manual detection of the lumen contour and the media-adventitia interface was undertaken by an experienced analyst blinded to baseline clinical characteristics and baseline angiographic characteristics of the lesions. The external elastic membrane volume and lumen volume were calculated. The difference between these two values was defined as PV.

VH-IVUS uses IVUS radiofrequency data to classify an atherosclerotic plaque into four compositions: fibrous, fibro-fatty, dense calcium, and necrotic core. These compositions are assigned color codes of green, greenish yellow, white and red, respectively. Color-coded tissue maps are then constructed. Compositions within the plaque can be identified, as previously validated by preliminary in-vitro and in-vivo studies [32,33]. Fibrous tissue was marked in green, fibro-fatty in yellow, dense calcium in white and necrotic core in red colors on the VH-IVUS image. The absolute value of each plaque composition was also calculated automatically by the software.

We compared the mean values of PV and plaque composition between baseline and follow-up in patients receiving statin therapy. We further analyzed the effects of statin treatment on plaque size by clinical presentation, dose and duration of statin treatment, and LDL-C levels at follow up.

\section{Statistical analyses}

We pooled treatment effects and calculated mean differences (MD) with a 95\% confidence interval (CI) for all endpoints by using a random-effects model [34]. 
Heterogeneity was tested using the Cochran Q test. We considered the results for heterogeneity to be significant at $P<0.10$ (two-sided). Inconsistency of treatment effects was calculated for assessing the percentage of total variance across studies that was due to heterogeneity rather than chance. Publication bias was estimated using funnel plots. A strongly asymmetric plot suggested the underlying presence of publication bias (i.e., whereby small studies reporting positive outcomes are more likely to be published than equally small studies reporting negative results). RevMan 5.0.23 was used for analyses of statistical data. $P<0.05$ was considered significant. For assessing the potential impact of publication bias, we calculated the fail-safe number using the method of Rosenberg and Orwin's [35]. (The fail-safe number represents the number of studies needed to make $P>0.05$.)

By stratified analyses, we explored the influence of clinical presentation, dose and duration of statin treatment, and LDL-C levels at follow-up on the effects of statins. Of the 22 groups, 5 groups investigated patients with acute coronary syndrome (ACS) and 13 groups investigated patients with stable angina pectoris (SAP). When considering the dose and duration of statin therapy, enrolled studies were divided into four subgroups: subgroup $1, \leq 10 \mathrm{mg} /$ day of atorvastatin or an equivalent dose of other statins and $\leq 6$ months of follow-up; subgroup $2, \leq 10 \mathrm{mg} /$ day of atorvastatin or an equivalent dose of other statins and $>6$ months of follow-up; subgroup $3,>10 \mathrm{mg} /$ day of atorvastatin or an equivalent dose of other statins and $\leq 6$ months of follow-up; and subgroup 4,>10 mg/day of atorvastatin or an equivalent dose of other statins and $>6$ months of follow-up. When considering LDL-C levels at follow-up, all enrolled studies were divided into three subgroups: subgroup 1, $\leq 70 \mathrm{mg} / \mathrm{dL}$ of LDL-C; subgroup 2, 70-100 $\mathrm{mg} / \mathrm{dL}$ of LDL-C; and subgroup 3, $\geq 100 \mathrm{mg} / \mathrm{dL}$ of LDL-C.

\section{Results}

Of the 22 groups, atorvastatin was used in 8 groups, rosuvastatin in 3 groups, simvastatin in 3 groups, pravastatin in 3 groups, pitavastatin in 1 group, fluvastatin in 1 group, and different statins in 3 groups (Additional file 3: Table S3). Each group enrolled mostly men. Of the 22 groups, 5 groups investigated patients with ACS, and 13 groups investigated patients with SAP. The remaining 4 groups did not exclude patients with ACS. The sample size of the studies was $17-446$ patients. The mean age of patients in the studies was $61 \pm 3.5$ years (range, 55-67 years). The mean LDL-C level at baseline was $128.6 \pm 22.6 \mathrm{mg} / \mathrm{dL}$ (range, $71-158.3 \mathrm{mg} / \mathrm{dL}$ ). The mean LDL-C level at follow-up ranged was $85.3 \pm$ $13.8 \mathrm{mg} / \mathrm{dL}$ (range, 60.8-110.4 mg/dL). The duration of follow up was 1.5-24 months.
The PV significantly decreased after statin therapy (MD: $-5.3 \mathrm{~mm}^{3}$; 95\% CI: -3.3 to $-7.2 \mathrm{~mm}^{3} ; P<0.001$ ), without heterogeneity $\left(P=0.83\right.$ and $I^{2}=0 \%$; Figure 2). The funnel plot (Figure 3 ) did not show asymmetry consistent with publication bias. The fail-safe $N$ was 142 , suggesting that 142 additional 'negative' studies would be needed to negate our result. The decrease in PV in ACS patients was twofold than that observed in SAP patients (Table 1 ).

A regressive trend was seen for necrotic core volume (MD: $-2.1 \mathrm{~mm}^{3}$; $95 \% \mathrm{CI}:-4.7 \mathrm{~mm}^{3}$ to $0.5 \mathrm{~mm}^{3}$, Figure 4$)$, but did not reach statistical significance $(P=$ $0.11)$. No significant change was noted for the fibrotic, fibro-fatty, or dense calcium volume $(P=0.87,0.59$, and 0.99 , respectively). Non-significant heterogeneity was detected for the fibrotic, necrotic core or dense calcium volume, but not for fibro-fatty volume $\left(I^{2}=91 \%\right)$.

When considering the dose and duration of statin therapy, a significant decrease in PV was seen only in the studies involving administration of $>10 \mathrm{mg} /$ day of atorvastatin or an equivalent dose of other statins and $>6$ months of continuous therapy (MD, $-5.2 \mathrm{~mm}^{3} ; 95 \%$ CI: $-3.1 \mathrm{~mm}^{3}$ to $-7.3 \mathrm{~mm}^{3} ; P<0.001$; fail-safe $N=45 ; 9$ groups, 1,520 patients; Table 2), without heterogeneity.

When considering LDL-C levels at follow-up, significant decreases in PV were shown in studies with 70$100 \mathrm{mg} / \mathrm{dL}$ of achieved LDL-C levels (MD: $-5.7 \mathrm{~mm}^{3}$; 95\% CI: $-2.7 \mathrm{~mm}^{3}$ to $-8.6 \mathrm{~mm}^{3} ; P<0.001$; fail-safe $N=$ 58 ; 13 groups, 1,372 patients; Table 3 ), and in the studies with $<70 \mathrm{mg} / \mathrm{dL}$ of achieved LDL-C levels (MD: $-5.9 \mathrm{~mm}^{3}$; $95 \% \mathrm{CI}:-2.2 \mathrm{~mm}^{3}$ to $-9.6 \mathrm{~mm}^{3} ; P<0.001$; fail-safe $N=5 ; 4$ groups, 429 patients; Table 3$)$. However, there was no a significant decrease in PV in studies with $>100 \mathrm{mg} / \mathrm{dL}$ of achieved LDL-C levels $(P=0.15)$. There was no evidence of heterogeneity for the three subgroups.

\section{Discussion}

The present study demonstrated that statin therapy can significantly decrease the size of atherosclerotic plaques, whereas there were no significant changes in plaque composition. These findings are similar to the findings in some in-vivo human studies [36]. Our findings are supported by animal studies, which have demonstrated a reduction in plaque size and macrophage content as well as an increase in the amount of interstitial collagen in atherosclerotic lesions after lipid-lowering therapy (LLT) [37-39]. One study demonstrated that PV increased by $11.8 \%$ in the usual care group [25]. When considering the dose and duration of statin therapy, a significant decrease in PV was noted only in subgroups having a high dose and long duration of statin therapy. Based on achieved LDL-C levels, the present study demonstrated that a significant decrease in plaque size will occur only 


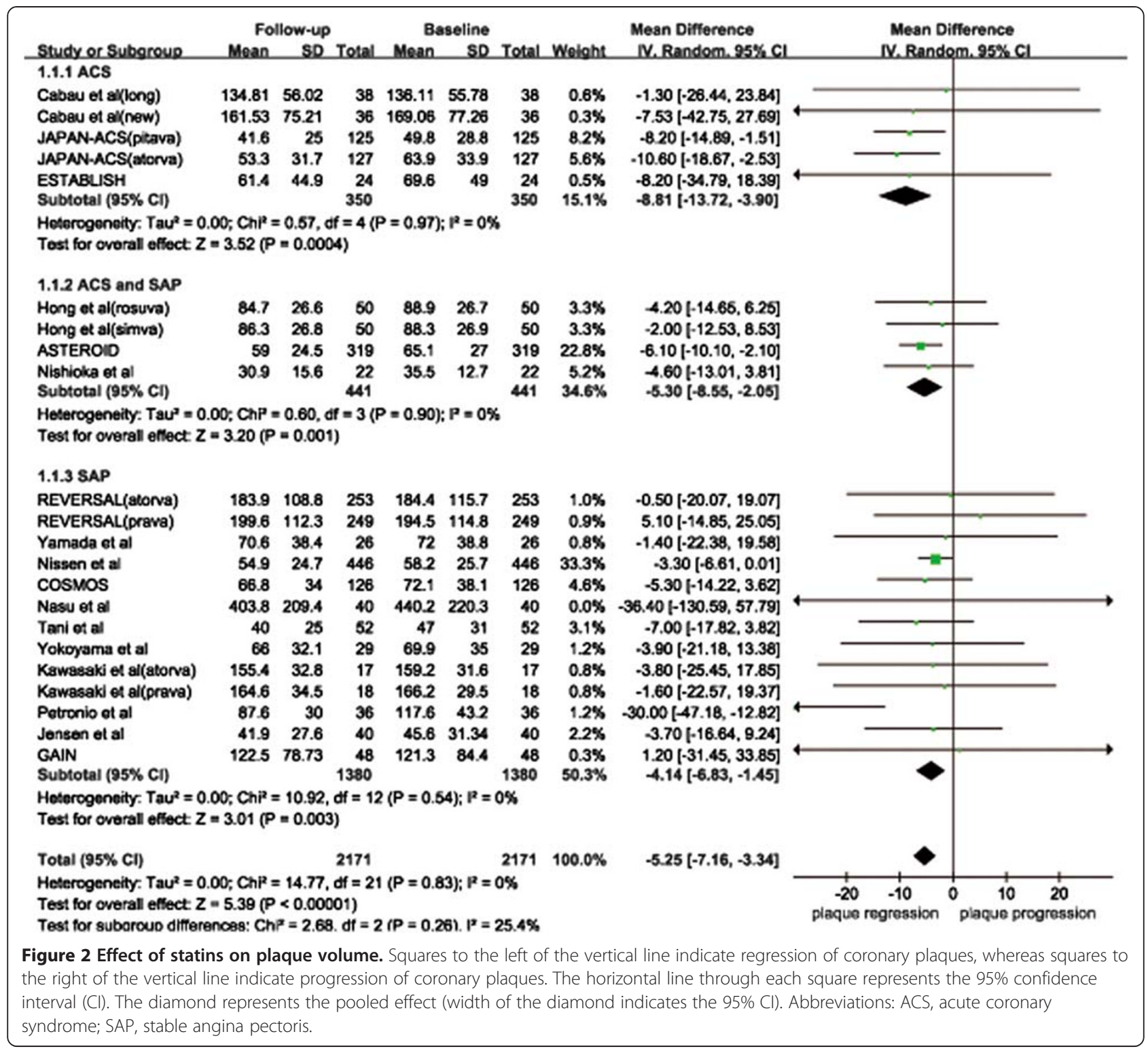

if LDL-C is $<100 \mathrm{mg} / \mathrm{dL}$. This finding supports the use of intensive LDC-L-lowering therapy in high-risk older subjects with established cardiovascular disease. These data indicate that coronary artery disease can be retarded (and even regress) if the favorable levels of LDL-C that were attained with statin therapy in the present study are achieved. Statin treatment induced a twofold decrease in PV in patients with ACS compared with that seen in patients with SAP, and this difference may originate from various plaque characteristics between the two cohorts [40]. Evidence suggests that patients with ACS have many greater-risk non-culprit plaques [41]. Multi-slice CT study has demonstrated that certain characteristics of vulnerable plaques (e.g., positive vascular remodeling and low plaque density) are more frequent in ACS lesions than in SAP lesions [42].
Some papers published since October 2010 further supported our conclusion that statin therapy can significantly retard or even decrease plaque progression in patients with coronary artery disease, especially when patients taking a high dose and long duration of statin regimen $[27,29,31]$.

Plaque composition is now seen as being much more important than plaque size and the severity of stenoses. Plaques containing a soft lipid-rich core are particularly dangerous because such plaques are unstable and vulnerable to rupture, whereby highly thrombogenic plaques are exposed to blood flow $[43,44]$. Plaques that are prone to rupture have a large lipid core, occupy $>40 \%$ of the total PV, and have a thin fibrous cap (diameter, $<65 \mu \mathrm{m}$ ) [45]. Reduction in the size of the necrotic core might be one of several requirements for plaque 


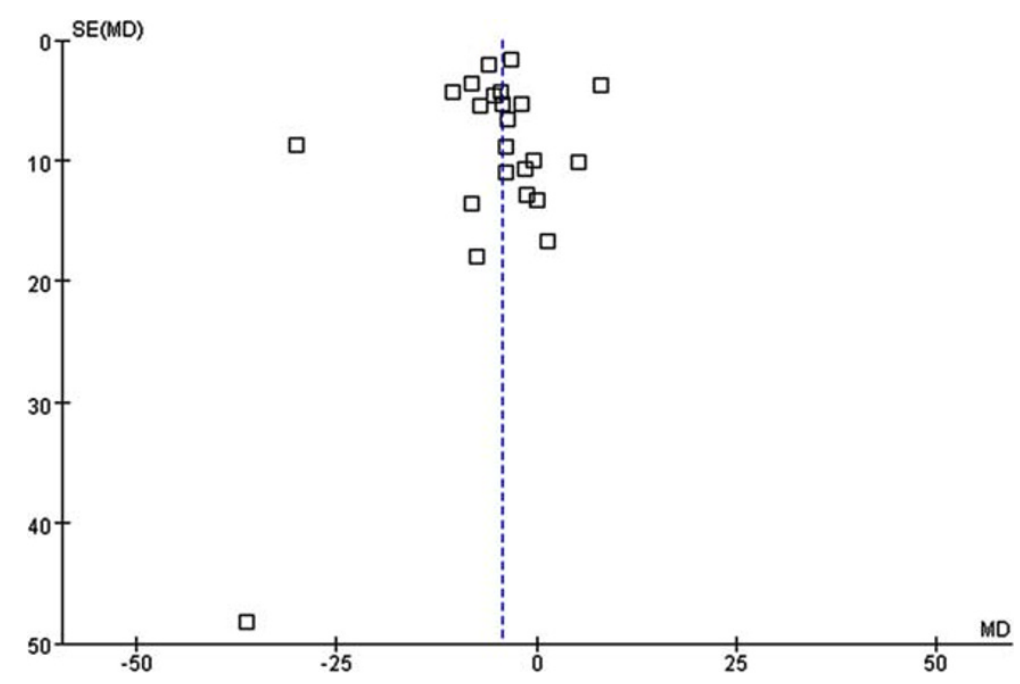

Figure 3 Graphical representation of publication bias. The dots, each representing one study, conform to a triangular shape: the publication bias is low.

stabilization. After statin therapy, the necrotic core tended to decrease in size, but this did not reach statistical significance. Some studies using optical coherence tomography (OCT) showed that the incidence of plaque rupture was significantly decreased and that the thickness of the fibrous cap tended to increase with statin therapy [46]. Based upon VH-IVUS findings, "fibrofatty" is defined as fibrous tissue with significant lipid interspersed in collagen [32]. The interspersed lipids in fibro-fatty tissue might regress from the atherosclerotic intima with a reducing continued influx of lipid. Hence, an accumulation of interstitial collagen in fibrous tissue might be significantly increased by LLT. However, we failed to observe significant changes in fibro-fatty volume in the present study. In agreement with our conclusion, one recent study has demonstrated that statins does not lead to significant changes in plaque composition [28]. One explanation for those findings in the present study could be that the dose of statins selected in the three groups should be almost equivalent to 10 $20 \mathrm{mg} /$ day of atorvastatin, which is relatively low to be effective for stabilizing coronary plaques in CHD $[13,14]$. Further studies are needed to determine the effect of intensive statin therapy on plaque composition. Another reason for those findings in the present study could be low statistical power. For primary efficacy, i.e., change in necrotic core volume, a sample size of $\approx 238$ patients was specified for $80 \%$ power and a two-sided $\alpha$ level of 0.025 to detect an expected change of $-2 \mathrm{~mm}^{3}$ (assuming a standard deviation (SD) of $10 \mathrm{~mm}^{3}$ ). Indeed, a substantial residual risk of clinical events remains in most patients who have undergone secondary prevention despite the use of statins [47]. In the Scandinavian Simvastatin Survival Study (4S), therapy reduced the relative risk of coronary events by $\approx 30 \%$ over 5 years from an absolute risk of $28 \%$ to $19 \%$ [48,49]. Novel antiatherosclerotic agents in addition to statins may be needed to more effectively stabilize plaque composition.

One study reported a non-significant decrease in PV in a subgroup with $<100 \mathrm{mg} / \mathrm{dL}$ LDL-C levels at follow-up and in a subgroup with $>6$ months of statin therapy; these data were probably due to a relatively small sample size and non-consideration of the consequences of statin dose [6]. Based on the achieved LDL-C levels, our subgroup analyses demonstrated significant plaque regression at a follow-up LDL-C level of $<100 \mathrm{mg} / \mathrm{dL}$. Those results support the efficacy of Adult Treatment Panel III (ATP III) Cholesterol Guidelines and improve the practice of lipid lowering with statins [50]. Recently, one IVUS study have reported that a positive association was noted between the changes in LDL-C and plaque volume [30]. Some landmark studies have also shown that high

Table 1 Mean differences and $95 \%$ Cls in plaque volume achieved in patients taking one statin

\begin{tabular}{|c|c|c|c|c|c|}
\hline Subgroup & Number of studies & Number of patients & $I^{2}$ index & PV change $(95 \% \mathrm{Cl})$ & $P$ \\
\hline All patients & 19 & 2,171 & $0 \%$ & $-5.3 \mathrm{~mm}^{3}(-7.2,-3.3)$ & $<0.001$ \\
\hline ACS patients & 5 & 350 & $0 \%$ & $-8.8 \mathrm{~mm}^{3}(-13.7,-3.9)$ & 0.0004 \\
\hline SAP patients & 13 & 1,380 & $0 \%$ & $-4.1 \mathrm{~mm}^{3}(-6.8,-1.5)$ & 0.003 \\
\hline
\end{tabular}

Abbreviations: $A C S$, acute coronary syndrome; $P V$, plaque volume; $S A P$, stable angina pectoris; $P^{2}$ index: degree of heterogeneity in the meta-analysis. 


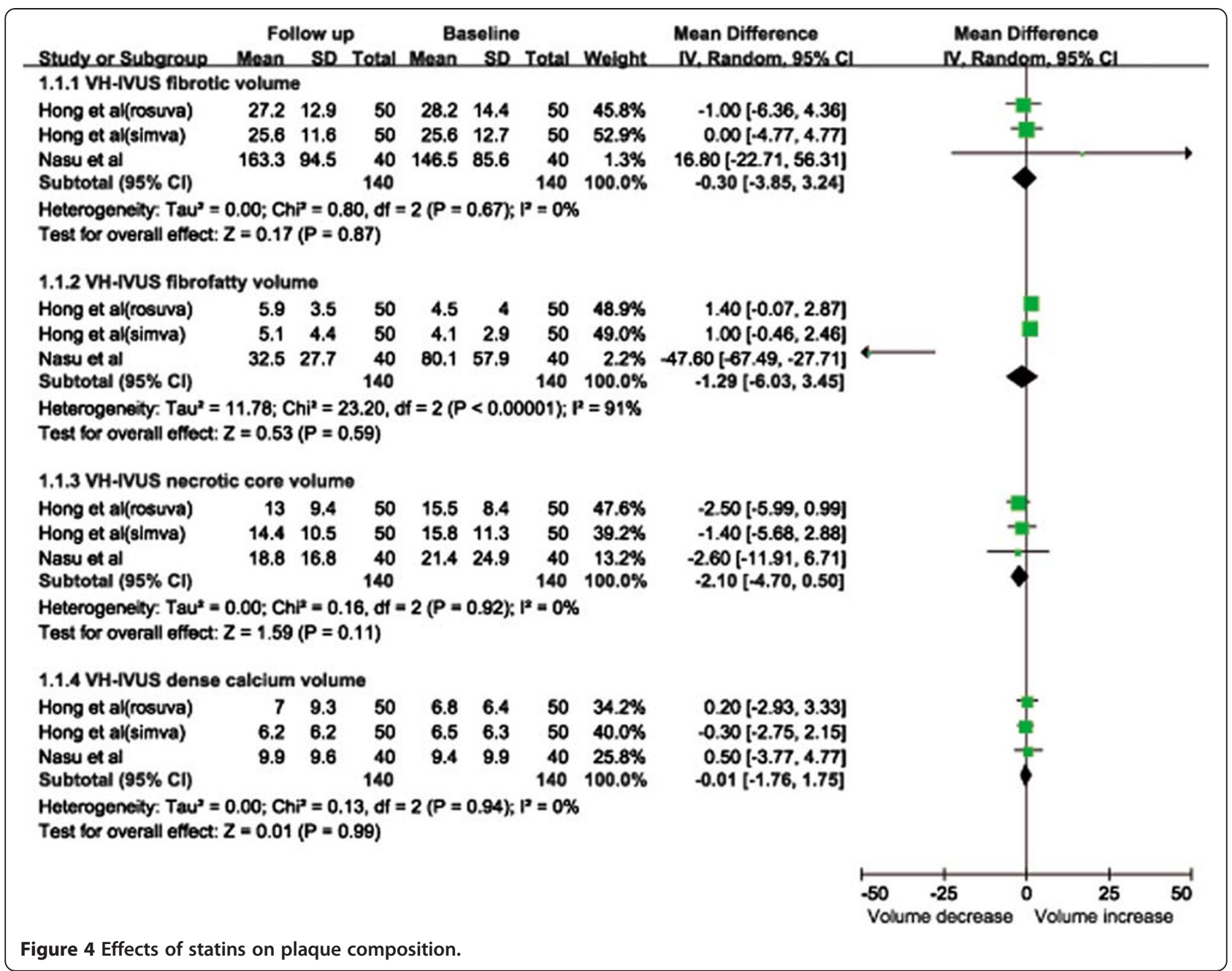

dose and long-term lipid-lowering with statins may be better for reducing cardiovascular adverse events in patients with cardiovascular disease [51-53]. Previous analyses suggest that benefit can be achieved by treating older patients with $\mathrm{CHD}$ more aggressively to reduce LDL-C levels to $<100 \mathrm{mg} / \mathrm{dL}$ [54]. Those benefits may be explained by the results in the present study which confirm that statin therapy at high dose over the long term are better for retarding and reversing atherosclerosis. The present study showed that, by appropriately selecting the regimen, statins can be used to reduce the atheroma burden for secondary prevention. The present study was based on large numbers of patients and had significant statistical power. No heterogeneity in treatment effects was observed for the main endpoints. Moreover, the funnel plot did not show asymmetry consistent with publication bias, and the fail-safe $N$ for the main endpoints was relatively large. Additionally, our results were not influenced by including the results of the ENCORE II study using $0.2-0.8 \mathrm{mg} /$ day of cerivastatin [9].

Table 2 Stratified analyses by dose and duration of follow-up of statin therapy

\begin{tabular}{|c|c|c|c|c|c|}
\hline Subgroup & Number of studies & Number of patients & $I^{2}$ index & PV change $(95 \% \mathrm{Cl})$ & $P$ \\
\hline 1 & 3 & 99 & $0 \%$ & $-5.4 \mathrm{~mm}^{3}(-13.8,3.0)$ & 0.21 \\
\hline 2 & 5 & 415 & $59 \%$ & $-7.8 \mathrm{~mm}^{3}(-20.2,4.5)$ & 0.21 \\
\hline 3 & 2 & 41 & $0 \%$ & $-5.6 \mathrm{~mm}^{3}(-22.3,11.2)$ & 0.52 \\
\hline 4 & 9 & 1,520 & $0 \%$ & $-5.2 \mathrm{~mm}^{3}(-7.3,-3.1)$ & $<0.001$ \\
\hline
\end{tabular}

Abbreviations: $P V$, plaque volume. Subgroup 1: $\leq 10 \mathrm{mg} /$ day of atorvastatin or an equivalent dose of other statins and $\leq 6 \mathrm{months}$ of follow-up; subgroup 2 : $\leq 10 \mathrm{mg} /$ day of atorvastatin or an equivalent dose of other statins and $>6$ months of follow-up; subgroup 3: $>10 \mathrm{mg} / \mathrm{day}$ of atorvastatin or an equivalent dose of other statins and $\leq 6$ months of follow-up; subgroup 4: $>10 \mathrm{mg} /$ day of atorvastatin or an equivalent dose of other statins and $>6$ months of follow-up. $l^{2}$ index: degree of heterogeneity in the meta-analysis. 
Table 3 Stratified analyses by LDL-C levels at follow-up

\begin{tabular}{|c|c|c|c|c|c|}
\hline Subgroup & Number of studies & Number of patients & $I^{2}$ index & PV change $(95 \% \mathrm{Cl})$ & $P$ \\
\hline$\leq 70 \mathrm{mg} / \mathrm{dL}$ of LDL-C & 4 & 429 & $0 \%$ & $-5.9 \mathrm{~mm}^{3}(-9.6,-2.3)$ & $<0.001$ \\
\hline 70-100 mg/dL of LDL-C & 13 & 1,372 & $9 \%$ & $-5.7 \mathrm{~mm}^{3}(-8.6,-2.7)$ & $<0.001$ \\
\hline$\geq 100 \mathrm{mg} / \mathrm{dL}$ of LDL-C & 5 & 370 & $0 \%$ & $-4.2 \mathrm{~mm}^{3}(-9.9,1.5)$ & 0.15 \\
\hline
\end{tabular}

Abbreviations: $L D L-C$, low-density lipoprotein-cholesterol; $P V$, plaque volume. $I^{2}$ index: degree of heterogeneity in the meta-analysis.

It has been suggested that statin administration can decrease plaque size, lipid content, and the thickness of the fibrous cap [55-57]. Nevertheless, the mechanisms by which statins contribute to plaque stabilization and atherosclerotic regression are incompletely understood. Recently, OCT, integrated backscatter intravascular ultrasound (IB-IVUS), VH-IVUS, and angioscopy have been shown to provide in-vivo real-time qualitative information of atheromas, such as lipid content, fibrouscap thickness, calcification, macrophage infiltration, thrombosis, and rupture [58-60]. Therefore, investigators could design large-scale studies to elucidate the changes in the size and composition of plaques after LLT with statins by combining these catheter-based intravascular imaging tools.

Some researchers have paid close attention to the pleiotropic effects of statins that are independent of lipid lowering effects. These include immune modulation, inhibition of the proliferation and migration of smooth muscle cells, and inhibition of angiogenesis [61-65]. The primary action of statins is a cholesterol-dependent effect: inhibition of the synthesis of L-mevalonate (a precursor of cholesterol). The secondary actions are pleiotropic: inhibition of the synthesis of isoprenoids such as farnesyl pyrophosphate and geranylgeranyl pyrophosphate (which are essential for membrane translocation and the biological activity of members of the GTPase family) [66,67]. Williams et al. documented that pravastatin-treated monkeys had atherosclerotic lesions with less neovascularization and less infiltration of macrophages independent of plasma concentrations of lipoproteins [37]. Atorvastatin treatment has been shown to dose-dependently reduce the level of a serum marker of oxidative stress [68]. Furthermore, those pleiotropic effects of statins are often larger with high doses of statins, and there may be individual differences among different statins [69]. The present study has shown that regimens employing high doses of statin result in plaque regression in subjects with $\mathrm{CHD}$. The dose-dependent pleiotropic effects of statins may be one of the explanations for our findings [70]. In the present study, greater benefit was noted among patients with ACS, which led to an improvement in outcome [71]. The pleiotropic effects of statins (particularly their anti-inflammatory and antithrombotic properties) have been invoked to explain the greater benefits seen in ACS [72,73]. However, it remains unclear which statin has the greatest and most rapid pleiotropic effects. Large, prospective, controlled studies are needed to determine the role of the pleiotropic effects of statins on atherosclerosis.

Our systematic review and meta-analysis had limitations. First, as is true with all systematic reviewed and meta-analyses, our study may have been affected by publication bias (though we did not find evidence of such bias). Second, the inclusion criteria of patients in primary studies (including those in the present study) were not standardized (e.g., LDL-C levels at baseline and clinical presentation). Third, although the studies included in this meta-analysis were homogeneous, variations in the dose, type, and duration of statin use among studies might have affected our results. Our random-effects model attempted to account for between-study variability, and the effects of this heterogeneity were examined.

\section{Conclusions}

Statins are prescribed extensively for the treatment of hypercholesterolemia. Our meta-analysis demonstrated that statin therapy (especially at a high dose and of long duration) can induce a significant decrease in PV. Based on the achieved LDL-C levels, subgroup analyses demonstrated significant plaque regression at a followup LDL-C level of $<100 \mathrm{mg} / \mathrm{dL}$. We also showed that statin treatment can induce a twofold decrease in PV in patients with ACS compared with that seen in patients with SAP. However, no significant change in plaque composition was seen after statin therapy.

\section{Additional files}

Additional file 1: Table S1. General characteristic of the 5 studies including 7 groups without formal analysis.

Additional file 2: Table S2. (VH)-IVUS findings at baseline and followup in patients taking one statin from 5 studies without formal analysis.

Additional file 3: Table S3. General characteristic of the included studies.

\section{Abbreviations}

ACS: Acute coronary syndrome; CHD: Coronary heart disease; $\mathrm{Cl}$ : Confidence interval; IVUS: Intravascular ultrasound; MD: Mean differences; LDL-C: Lowdensity lipoprotein-cholesterol; LLT: Lipid-lowering therapy; OCT: Optical coherence tomography; PV: Plaque volume; SAP: Stable angina pectoris; $\mathrm{VH}$ : Virtual histology. 


\section{Competing interests}

The authors declare that they have no competing interests.

\section{Authors' contributions}

BY conceived of the study idea, and BY, JT, XG, and YS contributed to the study design. $X G$ conducted the literature review. JT, SH, and $Y X$ performed the data extraction. BY, YS, JT, and XB were involved in consensus agreements concerning data discrepancies. $Y X$ designed and $Y X$ and JT conducted the statistical analyses. $X B, Y X$, and $S H$ participated in interpretation of data. JT, BY, and $\mathrm{XB}$ drafted and revised the manuscript. All authors were involved in revising the article for important intellectual content, interpreting the data, and approved the final version to be published. All authors read and approved the final manuscript.

\section{Author details}

${ }^{1}$ Key Laboratories of Education Ministry for Myocardial Ischemia; Department of Cardiology, Second Affiliated Hospital of Harbin Medical University, Harbin 150086, P.R. China. ${ }^{2}$ Department of Pathology, Harbin Medical University, Harbin, China. ${ }^{3}$ Department of Bioinformatics, Harbin Medical University, Harbin, China.

Received: 20 December 2011 Accepted: 29 August 2012

Published: 1 September 2012

\section{References}

1. Collins R, Armitage J, Parish S, Sleigh P, Peto R: MRC/BHF Heart Protection Study of cholesterol-lowering with simvastatin in 5963 people with diabetes: a randomised placebo-controlled trial. Lancet 2003, 361:2005-2016.

2. Cannon CP, Braunwald E, McCabe CH, Rader DJ, Rouleau JL, Belder R, Joyal SV, Hill KA, Pfeffer MA, Skene AM: Intensive versus moderate lipid lowering with statins after acute coronary syndromes. N Engl J Med 2004, 350:1495-1504.

3. Ridker PM, Danielson E, Fonseca FA, Genest J, Gotto AM Jr, Kastelein JJ, Koenig W, Libby P, Lorenzatti AJ, Macfadyen JG, Nordestgaard BG, Shepherd J, Willerson JT, Glynn RJ: Reduction in C-reactive protein and LDL cholesterol and cardiovascular event rates after initiation of rosuvastatin: a prospective study of the JUPITER trial. Lancet 2009, 373:1175-1182.

4. Scott G, Diane B, Luther C, Richard C, Margo D, Wm H, Donald H, Illingworth DR, Russell L, Patrick M, James M, Richard P, Neil S, Linda H: Executive Summary of The Third Report of The National Cholesterol Education Program (NCEP) Expert Panel on Detection, Evaluation, And Treatment of High Blood Cholesterol In Adults (Adult Treatment Panel III). JAMA 2001, 285:2486-2497.

5. Simoons L, Saelman M: Effect of simvastatin on coronary atheroma: the Multicentre Anti-Atheroma Study (MAAS). Lancet 1994, 344:633-638.

6. Rodriguez-Granillo GA, Agostoni P, Garcia-Garcia HM, Biondi-Zoccai GG, McFadden E, Amoroso G, de Jaegere P, Bruining N, de Feyter P, Serruys PW: Meta-analysis of the studies assessing temporal changes in coronary plaque volume using intravascular ultrasound. Am J Cardiol 2007, 99:5-10.

7. Shiota M, Kusakabe H, Hikita Y, Nakao T, Izumi Y, Iwao H: Pharmacogenomics of cardiovascular pharmacology: molecular network analysis in pleiotropic effects of statin - an experimental elucidation of the pharmacologic action from protein-protein interaction analysis. J Pharmacol Sci 2008, 107:15-19.

8. Toi T, Taguchi I, Yoneda S, Kageyama M, Kikuchi A, Tokura M, Kanaya T, Abe S, Matsuda R, Kaneko N: Early effect of lipid-lowering therapy with pitavastatin on regression of coronary atherosclerotic plaque. Comparison with atorvastatin. Circ J 2009, 73:1466-1472.

9. Luscher TF, Pieper M, Tendera M, Vrolix M, Rutsch W, van den Branden F, Gi R, Bischoff KO, Haude M, Fischer D, Meinertz T, Münzel T: A randomized placebo-controlled study on the effect of nifedipine on coronary endothelial function and plaque formation in patients with coronary artery disease: the ENCORE II study. Eur Heart J 2009, 30:1590-1597.

10. Takayama T, Hiro T, Yamagishi M, Daida H, Hirayama A, Saito S, Yamaguchi T, Matsuzaki M: Effect of rosuvastatin on coronary atheroma in stable coronary artery disease: multicenter coronary atherosclerosis study measuring effects of rosuvastatin using intravascular ultrasound in Japanese subjects (COSMOS). Circ J 2009, 73:2110-2117.

11. Rodes-Cabau J, Tardif JC, Cossette M, Bertrand OF, Ibrahim R, Larose E, Gregoire J, L'Allier PL, Guertin MC: Acute effects of statin therapy on coronary atherosclerosis following an acute coronary syndrome. Am J Cardiol 2009, 104:750-757.

12. Hiro T, Kimura T, Morimoto T, Miyauchi K, Nakagawa $Y$, Yamagishi M, Ozaki Y, Kimura K, Saito S, Yamaguchi T, Daida H, Matsuzaki M: Effect of intensive statin therapy on regression of coronary atherosclerosis in patients with acute coronary syndrome: a multicenter randomized trial evaluated by volumetric intravascular ultrasound using pitavastatin versus atorvastatin (JAPAN-ACS [Japan assessment of pitavastatin and atorvastatin in acute coronary syndrome] study). J Am Coll Cardiol 2009, 54:293-302.

13. Nasu K, Tsuchikane E, Katoh O, Tanaka N, Kimura M, Ehara M, Kinoshita Y, Matsubara T, Matsuo H, Asakura K, Asakura Y, Terashima M, Takayama T, Honye J, Hirayama A, Saito S, Suzuki T: Effect of fluvastatin on progression of coronary atherosclerotic plaque evaluated by virtual histology intravascular ultrasound. JACC Cardiovasc Interv 2009, 2:689-696.

14. Hong MK, Park DW, Lee CW, Lee SW, Kim YH, Kang DH, Song JK, Kim JJ, Park SW, Park SJ: Effects of statin treatments on coronary plaques assessed by volumetric virtual histology intravascular ultrasound analysis. JACC CardiovasC Interv 2009, 2:679-688.

15. Yamada T, Azuma A, Sasaki S, Sawada T, Matsubara H: Randomized evaluation of atorvastatin in patients with coronary heart disease: a serial intravascular ultrasound study. Circ J 2007, 71:1845-1850.

16. Nissen SE, Nicholls SJ, Sipahi I, Libby P, Raichlen JS, Ballantyne CM, Davignon J, Erbel R, Fruchart JC, Tardif JC, Schoenhagen P, Crowe T, Cain V, Wolski K, Goormastic M, Tuzcu EM: Effect of very high-intensity statin therapy on regression of coronary atherosclerosis: the ASTEROID trial. JAMA 2006, 295:1556-1565.

17. Tani S, Watanabe I, Anazawa T, Kawamata H, Tachibana E, Furukawa K, Sato $Y$, Nagao K, Kanmatsuse K, Kushiro T: Effect of pravastatin on malondialdehyde-modified low-density lipoprotein levels and coronary plaque regression as determined by three-dimensional intravascular ultrasound. Am J Cardiol 2005, 96:1089-1094.

18. Yokoyama M, Komiyama N, Courtney BK, Nakayama T, Namikawa S, Kuriyama N, Koizumi T, Nameki M, Fitzgerald PJ, Komuro I: Plasma lowdensity lipoprotein reduction and structural effects on coronary atherosclerotic plaques by atorvastatin as clinically assessed with intravascular ultrasound radio-frequency signal analysis: a randomized prospective study. Am Heart J 2005, 150:287.

19. Kawasaki M, Sano K, Okubo M, Yokoyama H, Ito Y, Murata I, Tsuchiya K, Minatoguchi S, Zhou X, Fujita H, Fujiwara H: Volumetric quantitative analysis of tissue characteristics of coronary plaques after statin therapy using three-dimensional integrated backscatter intravascular ultrasound. J Am Coll Cardiol 2005, 45:1946-1953.

20. Petronio AS, Amoroso G, Limbruno U, Papini B, De Carlo M, Micheli A, Ciabatti N, Mariani M: Simvastatin does not inhibit intimal hyperplasia and restenosis but promotes plaque regression in normocholesterolemic patients undergoing coronary stenting: a randomized study with intravascular ultrasound. Am Heart J 2005, 149:520-526.

21. Nishioka H, Shimada K, Kataoka T, Hirose M, Asawa K, Hasegawa T, Yamashita H, Ehara S, Kamimori K, Sakamoto T, Kobayashi Y, Yoshimura T, Yoshiyama M, Takeuchi K, Yoshikawa J: Impact of HMG-CoA reductase inhibitors for non-treated coronary segments. Osaka City Med J 2004, 50:61-68.

22. Okazaki S, Yokoyama T, Miyauchi K, Shimada K, Kurata T, Sato H, Daida $\mathrm{H}$ : Early statin treatment in patients with acute coronary syndrome: demonstration of the beneficial effect on atherosclerotic lesions by serial volumetric intravascular ultrasound analysis during half a year after coronary event: the ESTABLISH Study. Circulation 2004, 110:1061-1068

23. Jensen LO, Thayssen P, Pedersen KE, Stender S, Haghfelt T: Regression of coronary atherosclerosis by simvastatin: a serial intravascular ultrasound study. Circulation 2004, 110:265-270.

24. Nissen SE, Tuzcu EM, Schoenhagen P, Brown BG, Ganz P, Vogel RA, Crowe T, Howard G, Cooper CJ, Brodie B, Grines CL, DeMaria AN: Effect of intensive compared with moderate lipid-lowering therapy on progression of coronary atherosclerosis: a randomized controlled trial. JAMA 2004, 291:1071-1080.

25. Schartl M, Bocksch W, Koschyk DH, Voelker W, Karsch KR, Kreuzer J, Hausmann D, Beckmann S, Gross M: Use of Intravascular Ultrasound to Compare Effects of Different Strategies of Lipid-Lowering Therapy on Plaque Volume and Composition in Patients With Coronary Artery Disease. Circulation 2001, 104:387-392. 
26. Nissen SE, Tardif JC, Nicholls SJ, Revkin JH, Shear CL, Duggan WT, Ruzyllo W, Bachinsky WB, Lasala GP, Tuzcu EM: Effect of torcetrapib on the progression of coronary atherosclerosis. N Engl J Med 2007, 356:1304-1316.

27. Lee K, Ahn TH, Kang WC, Han SH, Choi IS, Shin EK: The effects of statin and niacin on plaque stability, plaque regression, inflammation and oxidative stress in patients with mild to moderate coronary artery stenosis. Korean Circ J 2011, 41:641-648.

28. Kovarnik T, Mintz GS, Skalicka H, Kral A, Horak J, Skulec R, Uhrova J, Martasek P, Downe RW, Wahle A, Sonka M, Mrazek V, Aschermann M, Linhart A: Virtual histology evaluation of atherosclerosis regression during atorvastatin and ezetimibe administration: HEAVEN study. Circ J 2012, 76:176-183.

29. Hirayama A, Saito S, Ueda Y, Takayama T, Honye J, Komatsu S, Yamaguchi O, Li Y, Yajima J, Nanto S, Takazawa K, Kodama K: Plaque-stabilizing effect of atorvastatin is stronger for plaques evaluated as more unstable by angioscopy and intravenous ultrasound. Circ J 2011, 75:1448-1454.

30. Hong YJ, Jeong MH, Hachinohe D, Ahmed K, Choi YH, Cho SH, Hwang SH, Ko JS, Lee MG, Park KH, Sim DS, Yoon NS, Yoon HJ, Kim KH, Park HW, Kim $J$, Ahn Y, Cho JG, Park JC, Kang JC: Comparison of effects of rosuvastatin and atorvastatin on plaque regression in Korean patients with untreated intermediate coronary stenosis. Circ J 2011, 75:398-406.

31. Nicholls SJ, Ballantyne CM, Barter PJ, Chapman MJ, Erbel RM, Libby P, Raichlen JS, Uno K, Borgman M, Wolski K, Nissen SE: Effect of two intensive statin regimens on progression of coronary disease. N Engl J Med 2011, 365:2078-2087.

32. Nair A, Kuban BD, Tuzcu EM, Schoenhagen P, Nissen SE, Vince DG: Coronary plaque classification with intravascular ultrasound radiofrequency data analysis. Circulation 2002, 106:2200-2206.

33. Nasu K, Tsuchikane E, Katoh O, Vince DG, Virmani R, Surmely JF, Murata A, Takeda Y, Ito T, Ehara M, Matsubara T, Terashima M, Suzuki T: Accuracy of in vivo coronary plaque morphology assessment: a validation study of in vivo virtual histology compared with in vitro histopathology. J Am Coll Cardiol 2006, 47:2405-2412

34. DerSimonian R, Laird N: Meta-analysis in clinical trials. Control Clin Trials 1986, 7:177-188.

35. Rosenberg MS: The file-drawer problem revisited: a general weighted method for calculating fail-safe numbers in meta-analysis. Evolution 2005, 59:464-468.

36. Zhao XQ, Dong L, Hatsukami T, Phan BA, Chu B, Moore A, Lane T, Neradilek MB, Polissar N, Monick D, Lee C, Underhill H, Yuan C: MR imaging of carotid plaque composition during lipid-lowering therapy a prospective assessment of effect and time course. JACC Cardiovasc Imaging 2011, 4:977-986.

37. Williams JK, Sukhova GK, Herrington DM, Libby P: Pravastatin has cholesterol-lowering independent effects on the artery wall of atherosclerotic monkeys. J Am Coll Cardiol 1998, 31:684-691.

38. Shiomi M, Ito T, Tsukada T, Yata T, Watanabe $Y$, Tsujita Y, Fukami M, Fukushige J, Hosokawa T, Tamura A: Reduction of serum cholesterol levels alters lesional composition of atherosclerotic plaques. Effect of pravastatin sodium on atherosclerosis in mature WHHL rabbits. Arterioscler Thromb Vasc Biol 1995, 15:1938-1944.

39. Zhou G, Ge S, Liu D, Xu G, Zhang R, Yin Q, Zhu W, Chen J, Liu X Atorvastatin reduces plaque vulnerability in an atherosclerotic rabbit model by altering the 5-lipoxygenase pathway. Cardiology 2010, 115:221-228.

40. Jang IK, Tearney GJ, MacNeill B, Takano M, Moselewski F, Iftima N, Shishkov M, Houser S, Aretz HT, Halpern EF, Bouma BE: In vivo characterization of coronary atherosclerotic plaque by use of optical coherence tomography. Circulation 2005, 111:1551-1555.

41. Burke AP, Farb A, Malcom GT, Liang YH, Smialek J, Virmani R: Coronary risk factors and plaque morphology in men with coronary disease who died suddenly. N Engl J Med 1997, 336:1276-1282.

42. Motoyama S, Kondo T, Sarai M, Sugiura A, Harigaya H, Sato T, Inoue K, Okumura M, Ishii J, Anno H, Virmani R, Ozaki Y, Hishida H, Narula J: Multislice computed tomographic characteristics of coronary lesions in acute coronary syndromes. J Am Coll Cardiol 2007, 50:319-326.

43. van Lammeren GW, Reichmann BL, Moll FL, Bots ML, de Kleijn DP, de Vries JP, Pasterkamp G, de Borst GJ: Atherosclerotic plaque vulnerability as an explanation for the increased risk of stroke in elderly undergoing carotid artery stenting. Stroke 2011, 42:2550-2555.
44. Falk E, Shah PK, Fuster V: Coronary plaque disruption. Circulation 1995, 92:657-671.

45. Virmani R, Burke AP, Farb A, Kolodgie FD: Pathology of the vulnerable plaque. J Am Coll Cardiol 2006, 47(8 Suppl):C13-C18.

46. Hattori K, Ozaki Y, Ismail TF, Okumura M, Naruse H, Kan S, Ishikawa M, Kawai T, Ohta M, Kawai H, Hashimoto T, Takagi Y, Ishii J, Serruys PW, Narula J: Impact of statin therapy on plaque characteristics as assessed by serial OCT, grayscale and integrated backscatter-IVUS. JACC Cardiovasc Imaging 2012, 5:169-177

47. Fabbri G, Maggioni AP: Cardiovascular risk reduction: what do recent trials with rosuvastatin tell us? Adv Ther 2009, 26:469-487.

48. Kjekshus J, Pedersen TR: Reducing the risk of coronary events: evidence from the Scandinavian Simvastatin Survival Study (4S). Am J Cardiol 1995, 76:64C-68C

49. Pedersen TR, Olsson AG, Faergeman O, Kjekshus J, Wedel H, Berg K, Wilhelmsen L, Haghfelt T, Thorgeirsson G, Pyorala K, Miettinen T, Christophersen B, Tobert JA, Musliner TA, Cook TJ: Lipoprotein changes and reduction in the incidence of major coronary heart disease events in the Scandinavian Simvastatin Survival Study (4S). Circulation 1998, 97:1453-1460.

50. Grundy SM, Cleeman Jl, Merz CN, Brewer HB Jr, Clark LT, Hunninghake DB, Pasternak RC, Smith SC Jr, Stone NJ: Implications of recent clinical trials for the National Cholesterol Education Program Adult Treatment Panel III guidelines. Circulation 2004, 110:227-239.

51. Tikkanen MJ, Szarek M, Fayyad R, Holme I, Cater NB, Faergeman O, Kastelein J, Olsson AG, Larsen ML, Lindahl C, Pedersen TR: Total cardiovascular disease burden: comparing intensive with moderate statin therapy insights from the IDEAL (Incremental Decrease in End Points Through Aggressive Lipid Lowering) trial. J Am Coll Cardiol 2009, 54:2353-2357.

52. Cannon CP, Steinberg BA, Murphy SA, Mega JL, Braunwald E: Meta-analysis of cardiovascular outcomes trials comparing intensive versus moderate statin therapy. J Am Coll Cardiol 2006, 48:438-445.

53. Nissen SE, Tuzcu EM, Schoenhagen P, Crowe T, Sasiela WJ, Tsai J, Orazem J, Magorien RD, O'Shaughnessy C, Ganz P: Statin therapy, LDL cholesterol, C-reactive protein, and coronary artery disease. N Engl J Med 2005, 352:29-38.

54. Wenger NK, Lewis SJ, Herrington DM, Bittner V, Welty FK: Outcomes of using high- or low-dose atorvastatin in patients 65 years of age or older with stable coronary heart disease. Ann Intern Med 2007, 147:1-9.

55. Pucci A, Sheiban I, Formato L, Celeste A, Brscic E, Moretti C, De Bernardi A, Alberti A, Bergamasco L, Trevi G, Fuster V: In vivo coronary plaque histology in patients with stable and acute coronary syndromes: relationships with hyperlipidemic status and statin treatment. Atherosclerosis 2007, 194:189-195.

56. Tokgozoglu L: Dyslipidemia, atherosclerosis, and vulnerable plaques: the effect of atorvastatin on atherosclerosis and plaque structure. Turk Kardiyol Dern Ars 2009, 37:11-16.

57. Imanishi T, Ikejima H, Tsujioka H, Kuroi A, Ishibashi K, Komukai K, Tanimoto $T$, Ino Y, Takeshita T, Akasaka T: Association of monocyte subset counts with coronary fibrous cap thickness in patients with unstable angina pectoris. Atherosclerosis 2010, 212:628-635.

58. Kubo T, Akasaka T: Recent advances in intracoronary imaging techniques: focus on optical coherence tomography. Expert Rev Med Devices 2008, 5:691-697.

59. Sharif F, Murphy RT: Current status of vulnerable plaque detection. Catheter Cardiovasc Interv 2010, 75:135-144.

60. Matter CM, Stuber M, Nahrendorf M: Imaging of the unstable plaque: how far have we got? Eur Heart J 2009, 30:2566-2574.

61. Davidson MH: Clinical significance of statin pleiotropic effects: hypotheses versus evidence. Circulation 2005, 111:2280-2281.

62. Wang CY, Liu PY, Liao JK: Pleiotropic effects of statin therapy: molecular mechanisms and clinical results. Trends Mol Med 2008, 14:37-44.

63. Mihos CG, Santana O: Pleiotropic effects of the HMG-CoA reductase inhibitors. Int J Gen Med 2011, 4:261-271.

64. Koutouzis M, Nomikos A, Nikolidakis S, Tzavara V, Andrikopoulos V, Nikolaou $N$, Barbatis C, Kyriakides Z: Statin treated patients have reduced intraplaque angiogenesis in carotid endarterectomy specimens. Atherosclerosis 2007, 192:457-463.

65. Arnaud C, Mach F: Pleiotropic effects of statins in atherosclerosis: role on endothelial function, inflammation and immunomodulation. Arch Mal Coeur Vaiss 2005, 98:661-666. 
66. Vincent L, Chen W, Hong L, Mirshahi F, Mishal Z, Mirshahi-Khorassani T, Vannier JP, Soria J, Soria C: Inhibition of endothelial cell migration by cerivastatin, an HMG-CoA reductase inhibitor: contribution to its antiangiogenic effect. FEBS Lett 2001, 495:159-166.

67. Santana O, Mihos: Pleiotropic effects of the HMG-CoA reductase inhibitors. Int J Gen Med 2011, 4:261-271.

68. Fujita M, Yamazaki T, Hayashi D, Kohro T, Okada Y, Nagai R: Pleiotropic effects of statins on cardiovascular events in the Japanese Coronary Artery Disease study. Int J Cardiol 2008, 129:294-296.

69. Boodhwani M: High-dose atorvastatin improves hypercholesterolemic coronary endothelial dysfunction without improving the angiogenic response. Circulation 2006, 114:1402-1408.

70. Mays ME, Dujovne CA: Pleiotropic effects: should statins be considered an essential component in the treatment of dyslipidemia? Curr Atheroscler Rep 2008, 10:45-52

71. Schwartz GG, Olsson AG, Ezekowitz MD, Ganz P, Oliver MF, Waters D, Zeiher $A$, Chaitman BR, Leslie S, Stern T: Effects of atorvastatin on early recurrent ischemic events in acute coronary syndromes: the MIRACL study: a randomized controlled trial. JAMA 2001, 285:1711-1718.

72. Wiviott SD, de Lemos JA, Cannon CP, Blazing M, Murphy SA, McCabe CH, Califf $R$, Braunwald E: A tale of two trials: a comparison of the post-acute coronary syndrome lipid-lowering trials A to Z and PROVE IT-TIMI 22. Circulation 2006, 113:1406-1414.

73. Ray KK, Cannon CP: Early time to benefit with intensive statin treatment: could it be the pleiotropic effects? Am J Cardiol 2005, 96:54F-60F.

doi:10.1186/1471-2261-12-70

Cite this article as: Tian et al.: Effect of statin therapy on the progression of coronary atherosclerosis. BMC Cardiovascular Disorders 2012 12:70.

\section{Submit your next manuscript to BioMed Central and take full advantage of:}

- Convenient online submission

- Thorough peer review

- No space constraints or color figure charges

- Immediate publication on acceptance

- Inclusion in PubMed, CAS, Scopus and Google Scholar

- Research which is freely available for redistribution 